\title{
Factors Affecting Quality of Life and Work Productivity among Patients with Gout
}

\author{
Marwa Mosaad Ali ${ }^{1, *}$, Soha Kamel Mosbah ${ }^{2}$, Nehal Mahmoud Abo El-Fadl ${ }^{1}$ \\ ${ }^{1}$ Medical-Surgical Nursing, Benha University, Egypt \\ ${ }^{2}$ Community Health Nursing, Benha University, Egypt \\ *Corresponding author: medicine_s2000@Yahoo.com
}

Received November 17, 2018; Revised December 27, 2018; Accepted January 16, 2019

\begin{abstract}
Gout is the most common inflammatory arthritis today, affecting $4 \%$ of the adult US population. It is a serious disease that can significantly affect physical function and quality of life (QOL), where it has been advocated as an important outcome domain in studies of chronic gout. Aim of the study: To assess factors affecting quality of life and work productivity among patients with gout. Descriptive design: Was used to conduct the current study in rheumatology outpatient clinics, at Benha Teaching Hospital during the period from beginning of March 2018 till the beginning of September 2018. Subjects: Purposive sample of 168 patients recruited according to the study formula based on the total number of patients who admitted to the study settings during 2017. Tools: Three tools were utilized for data collection, structured interviewing questionnaire sheet, Medical Outcomes Study Questionnaire Short Form 36 Health Survey (SF-36) and Work Productivity and Activity Impairment Questionnaire. Results: Showed that both QOL as well as work productivity and activity impairment were best predicted by pain severity, diet aggravating frequency of attacks, nature of work as well as age. Besides, there was a negative and significant correlation $\left(\mathrm{p}=<0.001^{* *}\right)$ between quality of life and work productivity and activity impairment. Conclusion: Factors affecting QOL and Work productivity and activity impairment among patients with gout were concerning pain severity, diet aggravating frequency of attacks, nature of work as well as age. Besides, the impairment on different aspects of life is often negatively associated with impairment in work productivity and activity, where they were mainly affected by gout. Recommendation: Health educational instructions is required regarding pain management and diet regimen for patients with gout.
\end{abstract}

Keywords: gout, quality of life, work productivity

Cite This Article: Marwa Mosaad Ali, Soha Kamel Mosbah, and Nehal Mahmoud Abo El-Fadl, "Factors Affecting Quality of Life and Work Productivity among Patients with Gout." American Journal of Nursing Research, vol. 7, no. 2 (2019): 128-135. doi: 10.12691/ajnr-7-2-4.

\section{Introduction}

Gout is a type of arthritis that causes inflammation, usually in one joint, that begins suddenly, caused by elevated levels of uric acid in the blood (hyperuricemia), with persistence of hyperuricemia at levels higher than a serum saturation of $6.8 \mathrm{mg} / \mathrm{dl}$ leading to deposit of urates on articular cartilage. The body produces uric acid when it breaks down purines that are found naturally in the body, it is also found in certain foods, such as steak, organ meats and seafood $[1,2]$.

Gout flares start suddenly and can last days or weeks, followed by long periods of time (weeks, months, or years) without symptoms before another flare begins. It usually occurs in only one joint at a time. It is often found in the big toe. Along with the big toe, joints that are commonly affected are the lesser toe joints, the ankle, and the knee. Symptoms in the affected joint(s) may include: nodules under the skin called tophi, redness, swollen, pain, and warmth of the joint [3].
There are many risk factors of gout are such as; Diet, where the risk is increased by the frequent consumption of foods high in purines, including meats, seafood, certain vegetables andbeans, and foods containing fructose. Also, women are less likely to have gout than men, however, especially after menopause. Regarding, Family history genetics play a role, making some people's bodies more prone to accumulating uric acid and developing the uric acid crystals that lead to gout. Excess weight, has a greater risk of developing gout. Besides, Lead exposure has a higher incidence of gout. As well as, taking certain medications can increase the risk of gout, as diuretics, aspirin, cyclosporine, and levodopa. So, controlling these factors decreasing not only the sufferings associated with gout, but also improving quality of life [4].

Although gout is a preventable and treatable disease but without treatment it leads to many life style disruptions such as erosion and deformity of a joint, disability, sleep disturbance, kidney stones. Also, untreated gout may cause deposits of urate crystals to form under the skin in nodules called tophi. These occur most often in the hands, feet, wrists, ankles, and ears. Tophi feel like hard bumps 
under the skin and are usually not painful, except during gout attacks when they become inflamed and swollen, so effective treatment improves QOL [5,6].

It has significant impact on physical function, productivity, quality of life (QOL) and health care costs. Therefore, it is critical to understand the specific impact of gout on patients' lives. To date, qualitative research in gout has focused on examining patients' knowledge related to gout, patterns of treatment and the barriers to treatment adherence. While, there is a lack of in-depth studies assessing the impact of gout on QOL, also has a substantial impact on work absence and may also negatively impact productivity, considering one spends most of the day performing work-related activities, which require both physical and psychological energy. Thus, in order to increase productivity, it is essential to invest patients' quality of life $[7,8]$.

Meanwhile, nurses as the greatest health profession group compared to other members of the health care team, where their led interventions have shown significant improvement in reaching urate goals, have a more comprehensive understanding of educational needs of those patients and they are more able to follow them up, manage their gout symptoms and improve their quality of life. Also, The Nurses' educator role is also strongly supported. As revealed in a study of patients' perceptions of drug information given by a rheumatology nurse, and was found that the patients achieved a sense of "autonomy, power and security $[9,10]$.

\subsection{Significance of the Study}

Gout is a chief public health care in both developing and developed countries. It affects approximately more than 8 million Americans. It accounts for approximately 7 million ambulatory visits in the United States.Several studies suggest that its prevalence and incidence have risen in recent decades. Numerous risk factors for the development of gout have been established, including hyperuricaemia, genetic factors, dietary factors, alcohol consumption, metabolic syndrome, hypertension, obesity, diuretic use and chronic renal disease $[11,12]$.

\subsection{Aim of the Study}

The aim of the present study was to assess factors affecting quality of life and work productivity among patients with gout.

\subsection{Research Questions}

To fulfill the aim of this study the following research questions were formulated:

$\mathbf{Q}_{1}-$ What are factors affecting quality of life?

$\mathbf{Q}_{2}$-What are factors affecting work productivity?

$\mathbf{Q}_{3}$ - Is there correlation between quality of life and work productivity?

\section{Subjects and Methods}

\subsection{Research Design}

Descriptive design was utilized to conduct the current study.

\subsection{Setting}

This study was conducted in rheumatology outpatient clinics at Benha Teaching Hospital.

\subsection{Subjects}

\subsubsection{Subject Type}

Purposive sample was utilized to conduct the current study.

\subsubsection{Subject Size}

The sample size was calculated based on the previous year census report of admission in outpatient clinics (Benha Teaching Hospital Census, 2017). The total number of subjects comprised 168 patients with gout attending the study settings utilizing the following formula [13].

$$
n=\frac{N}{1+N(e)^{2}}
$$

Where:

$\mathrm{n}=$ sample size

$\mathrm{N}=$ total population $(290)$

$\mathrm{e}=$ margin error $(0.05)$

The patients had been selected according to the following criteria: Age 20 years or older, both sexes (male and female), diagnosed with gout for at least one year, able to communicate, accept to participate in the study.

\subsection{Tools of Data Collection}

\section{Three tools were utilized for data collection.}

\subsubsection{Tool (1):}

Structured Interviewing Questionnaire Sheet: it was developed by researchers, and was divided into two parts:

Part I: Concerned with socio-demographic characteristics of the study subjects including; age, gender, marital status, education level, occupation, Nature of work, and Body mass index.

Part II: Illness related data such as; Co morbidity, time since diagnosis, number of attacks during the last year, diet aggravating frequency of attack, smoking,....etc.

\subsubsection{Tool (2):}

Medical Outcomes Study Questionnaire Short Form 36 Health Survey (SF-36) it was developed by [14], and translated into Arabic and tested for its validity and reliability by [15] is an indicator of overall health status. It consists of 36 questions in eight different domains: physical functioning (10 items), role limitation due to physical problems (4 items), bodily pain ( 2 items), general health perception ( 5 items), vitality ( 4 items), social functioning ( 2 items), role limitation due to emotional problems (3 items) and mental health (5 items). Items are scored on a varying 2- to 6-point Likert scale. The SF-36 also includes a single item measure of health transition or change. The scores are summed per domain and then transformed to a 0-100 score (higher scores $=$ better health). The first four domains can be summarized in the 
Physical Component Summary (PCS); the last can be summarized into the Mental Component Summary (MCS). Most of studies that examined the reliability of the SF_36 have exceeded $0.80[16,17]$. Estimates of reliability in the physical and mental sections are typically above 0.90 .

\subsubsection{Tool (3):}

Work Productivity and Activity Impairment Questionnaire: Specific Health Problem V2.0 (WPAI: SHP): used to ask about the effect of problem on ability to work and perform regular activities. It was developed by [18] and translated into Arabic by the researchers. The WPAI yields four types of scores: Absenteeism (work time missed), Presenteesism (impairment at work/reduced on-the-job effectiveness), Work productivity loss (overall work impairment / absenteeism plus presenteeism), and Activity Impairment Incorporating six questions that elicit the following: employment status; hours missed due to health problems; hours missed due to other reasons; hours actually worked; and two questions that measure the degree health problems affected productivity while working and regular daily activities, on a scale from 0 to 10 , with higher numbers indicating greater impairment and less productivity, i.e., worse outcomes, as follows: Scores:

Multiply scores by 100 to express in percentages.

Percent work time missed due to problem: Q2/(Q2+Q4)

Percent impairment while working due to problem: Q5/10.

Percent overall work impairment due to problem: $\mathrm{Q} 2 /(\mathrm{Q} 2+\mathrm{Q} 4)+[(1-(\mathrm{Q} 2 /(\mathrm{Q} 2+\mathrm{Q} 4))) \mathrm{x}(\mathrm{Q} 5 / 10)]$

Percent activity impairment due to problem: Q6/10.

\subsection{Methods}

\subsubsection{Tool Validity}

The content validity was done through five panels of experts in medical and community nursing for face and content validity, and their opinions were requested via an assessment form. The experts were asked to grade each item as "essential," "useful but inadequate" or "unnecessary". Modification was carried out according to the panel's judgment on the clarity of sentences and appropriateness of content. The percentage of consensus among experts regarding structured interviewing questionnaire sheet was 96\%, Medical Outcomes Study Questionnaire Short Form 36 Health Survey (SF-36) was 97\% and Work Productivity and Activity Impairment Questionnaire: Specific Health Problem V2.0 (WPAI:SHP)was 97\%.

\subsubsection{Pilot Study}

It was conducted on $10 \%$ of the total sample (17 patients), and they were excluded from the study sample. In order to test the feasibility and reliability of tools. Regarding cronbach alpha values for Medical Outcomes Study Questionnaire Short Form 36 Health Survey (SF-36), were as follows: 0.78-0.93 for the entire scale, 0.93 for physical functioning, 0.84 for role limitation due to physical problems, 0.78 for bodily pain, 0.78 for general health perception, 0.86 for vitality, 0.85 for social functioning, 0.83 for role limitation due to emotional problems, and 0.90 for mental health. In addition Work Productivity and Activity Impairment Questionnaire related cronbach alpha was 0.76 for the total scale.

\subsubsection{Ethical Considerations}

This study was conducted under the approval of the Faculty of Nursing Ethics Committee, Benha University. An explanation about the purpose of the study was given to participants, and they were also informed that they could withdraw from the study at any time before the completion of the study. After agreement for Participation in the study, participants were asked to sign a consent form. Moreover, they were reassured that all information gathered would be confidential and used only for the purpose of the study.

\subsubsection{Field of Work}

\section{Data were collected in the following sequence}

- An official permission to carry out the study was obtained from pertinent authorities after explanation of its purpose. Then, structured interview was conducted individually for patients eligible for the study (fulfilled the inclusion and exclusion criteria) in order to explain the purpose of the study, assure confidentiality and to obtain informed written consent.

- Data collection extended over a period of six months from beginning of March 2018 to beginning of September 2018. And data was collected for three days weekly (Sunday, Tuesday and Thursday) from 9am to $12 \mathrm{pm}$.

- Each patient with gout was interviewed individually to collect the patient's data using all study tools. This interview took about 25 to 30 minutes.

\subsubsection{Data Analysis}

The collected data were tabulated and statistically analyzed using an IBM computer and the statistical package for social science (SPSS) advanced statistics, version 20 (SPSS Inc., Chicago, IL). Numerical data were expressed as mean and standard deviation. Qualitative data were expressed as frequency and percentage. Linear regression was used for multivariate analyses on health related quality of life and work productivity as dependent factors. Pearson method was used to test correlation between numerical variables. A p-value $<0.05$ was considered significant, and $<0.001$ was considered highly significant.

\section{Results}

Table 1. Presents socio-demographic characteristics of patients under the study, it was observed that, the mean age of participants was $(45.74 \pm 6.87)$ years. It also shows that $(52.4 \%)$ were male and $(100.0 \%)$ were married, and $(77.4 \%)$ had secondary level of education. Besides, $(46.4 \%)$ had free work and $(61.9 \%)$ their work required physical effort, moreover $(45.8 \%)$ their body mass index was $30-32 \mathrm{k} / \mathrm{m}^{2}$ with a mean of $(31.46 \pm 1.62)$.

Table 2. Reveals illness related data of studied subjects which indicated that, $(61.9 \%)$ had comorbid disease and 
$(61.9 \%)$ were diagnosed with gout since five to ten years. Also, $(53.6 \%)$ had $<5$ attacks during the last year, $(74.4 \%)$ had polyarticular affection with $(82.1 \%)$ were complaining from acute pain in other joints as, ankle, knee, hands and pelvis during attack, especially in joints of foot among $(86.3 \%) \&(54.2 \%)$ of them had severe pain, as well as the most diet aggravating frequency of attacks was related to increased eating red meat and sea food among $(85.1 \%)$ of them, with $(61.9 \%)$ were irregularly visiting doctors for follow up.

Table 1. Distribution of the Studied Subjects According to Their Socio-Demographic Characteristics $(n=168)$

\begin{tabular}{|c|c|c|}
\hline $\begin{array}{l}\text { Socio-demographic } \\
\text { characteristics }\end{array}$ & (No.) & $(\%)$ \\
\hline \multicolumn{3}{|l|}{ Age / years } \\
\hline$<45$ & 77 & 45.8 \\
\hline $45+$ & 91 & 54.2 \\
\hline Mean \pm SD & \multicolumn{2}{|c|}{$45.74 \pm 6.87$} \\
\hline \multicolumn{3}{|l|}{ Gender } \\
\hline Male & 88 & 52.4 \\
\hline Female & 80 & 47.6 \\
\hline \multicolumn{3}{|l|}{ Marital status } \\
\hline Married & 168 & 100.0 \\
\hline \multicolumn{3}{|l|}{ Level of Education } \\
\hline Illiterate & 15 & 9.0 \\
\hline Basic education & 11 & 6.5 \\
\hline Secondary education & 130 & 77.4 \\
\hline University education & 12 & 7.1 \\
\hline \multicolumn{3}{|l|}{ Occupation } \\
\hline House wife & 26 & 15.5 \\
\hline Free work & 78 & 46.4 \\
\hline Employed & 64 & 38.1 \\
\hline \multicolumn{3}{|l|}{ Nature of work } \\
\hline Require physical effort & 104 & 61.9 \\
\hline Sedentary & 64 & 38.1 \\
\hline \multicolumn{3}{|l|}{ BMI } \\
\hline$<30 \mathrm{k} / \mathrm{m}^{2}$ & 26 & 15.5 \\
\hline $30-32 \mathrm{k} / \mathrm{m}^{2}$ & 77 & 45.8 \\
\hline$>32 \mathrm{k} / \mathrm{m}^{2}$ & 65 & 38.7 \\
\hline Mean \pm SD & \multicolumn{2}{|c|}{$31.46 \pm 1.62$} \\
\hline
\end{tabular}

Table 2. Distribution of the Studied Subjects According to Their Illness Related Data $(n=168)$

\begin{tabular}{|c|c|c|}
\hline Variables & No & $\%$ \\
\hline \multicolumn{3}{|l|}{ Presence of Co morbidities } \\
\hline No & 64 & 38.1 \\
\hline Yes & 104 & 61.9 \\
\hline \multicolumn{3}{|l|}{ Time since diagnosis } \\
\hline $1-<5$ year & 51 & 30.4 \\
\hline 5 years -10 years & 104 & 61.9 \\
\hline 10 years $>$ & 13 & 7.7 \\
\hline Mean \pm SD & \multicolumn{2}{|c|}{$5.88 \pm 3.00$} \\
\hline \multicolumn{3}{|l|}{ Stage of gout } \\
\hline Acute phase & 25 & 14.9 \\
\hline Chronic phase & 143 & 85.1 \\
\hline \multicolumn{3}{|c|}{ No of attacks during the last year } \\
\hline $5<$ & 90 & $\overline{53.6}$ \\
\hline $5 \geq$ & 78 & 46.4 \\
\hline Mean \pm SD & \multicolumn{2}{|c|}{$4.39 \pm 1.64$} \\
\hline \multicolumn{3}{|l|}{ History of articular affection } \\
\hline Oligoarticular & 43 & 25.6 \\
\hline Polyarticular & 125 & 74.4 \\
\hline \multicolumn{3}{|l|}{ Signs during attack } \\
\hline Acute pain in thumb of foot & 30 & 17.9 \\
\hline $\begin{array}{l}\text { Acute pain in other joints as, } \\
\text { ankle, knee, hands and pelvis }\end{array}$ & 138 & 82.1 \\
\hline \multicolumn{3}{|l|}{ Site of pain } \\
\hline Joints of foot & 145 & 86.3 \\
\hline Joints of foot and hands & 23 & 13.7 \\
\hline \multicolumn{3}{|l|}{ Pain severity } \\
\hline Moderate & 77 & 45.8 \\
\hline Severe & 91 & 54.2 \\
\hline \multicolumn{3}{|c|}{ Diet aggravating frequency of attack ( yes) } \\
\hline $\begin{array}{l}\text { Increased Eating red meat and } \\
\text { sea food }\end{array}$ & 143 & 85.1 \\
\hline Increased Eating Beans & 78 & 46.4 \\
\hline Drinking gas fluids & 65 & 38.7 \\
\hline \multicolumn{3}{|l|}{ Frequency of doctor's visits } \\
\hline Per 2 months & 64 & 38.1 \\
\hline Irregular visits & 104 & 61.9 \\
\hline \multicolumn{3}{|l|}{ Smoking } \\
\hline Never & 90 & 53.6 \\
\hline Smoking but quit now & 20 & 11.9 \\
\hline Continue to smoke & 58 & 34.5 \\
\hline
\end{tabular}

Table 3. Percent of mean of different dimensions for QOL among the studied subjects $(n=168)$

\begin{tabular}{|c|c|c|c|c|}
\hline \multirow{2}{*}{ Total scores of Dimensions } & \multicolumn{4}{|c|}{ Health related quality of life mean score } \\
\hline & $\mathbf{X}^{-} \pm \mathbf{S D}$ & Actual range & Total Score & Percentage of Total \\
\hline \multicolumn{5}{|l|}{ Physical Component Summary } \\
\hline a- Physical functioning & $16.20 \pm 3.81$ & $10-21$ & 30 & 54.0 \\
\hline b- Limitation due to physical health & $8.00 \pm 0.00$ & $8-8$ & 8 & 100.0 \\
\hline c- Bodily Pain & $8.39 \pm 1.01$ & $7-10$ & 10 & 83.9 \\
\hline d- General health & $15.69 \pm 0.72$ & $14-17$ & 25 & 62.76 \\
\hline \multicolumn{5}{|l|}{ Mental Component Summary } \\
\hline a- Limitation due to emotional problems & $6.00 \pm 0.00$ & $6-6$ & 6 & 100.0 \\
\hline b- Vitality (Energy/ fatigue) & $14.71 \pm 1.30$ & $11-16$ & 24 & 61.29 \\
\hline c- Emotional wellbeing (mental health) & $16.77 \pm 1.05$ & $15-18$ & 30 & 55.9 \\
\hline d- Social functioning & $6.15 \pm 0.36$ & $6-7$ & 10 & 61.5 \\
\hline Total & $91.93 \pm 4.63$ & $84-100$ & 143 & 64.29 \\
\hline
\end{tabular}


Table 4. Mean scores for work productivity and activity impairment among the studied subjects $(\mathrm{n}=168)$

\begin{tabular}{|c|c|c|c|}
\hline \multirow{2}{*}{ Items } & \multirow[t]{2}{*}{$\mathbf{N}$} & \multirow[t]{2}{*}{ Range } & $\begin{array}{c}\text { Work productivity and Activity } \\
\text { Impairment questionnaire }\end{array}$ \\
\hline & & & $\bar{X} \pm \mathrm{SD}$ \\
\hline \%Absenteeism (Work time missed due to gout) & 142 & $0.00-78.9$ & $52.8 \pm 26.7$ \\
\hline \%Presenteesism (impairment while working due to gout) & 168 & $0.00-80.0$ & $49.4 \pm 30.8$ \\
\hline \%Work productivity loss (overall work impairment due to gout) & 142 & $0.00-95.8$ & $74.3 \pm 30.8$ \\
\hline $\begin{array}{l}\text { \%Activity impairment due to problem (Missed activities with family/social due } \\
\text { to gout) }\end{array}$ & 168 & $0.00-80.0$ & $56.4 \pm 22.3$ \\
\hline
\end{tabular}

Table 5. Multiple linear regression analyses for predictor variables of quality of life among the studied subjects (n=168) ((B): Beta Co-Efficient, (SEB): Standard Error (BMI) body mass index)

\begin{tabular}{|c|c|c|c|c|c|}
\hline \multirow{2}{*}{ Predictor Variable } & \multicolumn{2}{|c|}{ Unstandardized Coefficients } & \multirow{2}{*}{$\begin{array}{c}\text { Standardized Coefficients } \\
\beta\end{array}$} & \multirow{2}{*}{$\mathbf{T}$} & \multirow{2}{*}{ p value } \\
\hline & B & SEB & & & \\
\hline Age & -4.25 & 0.37 & -1.96 & -11.45 & $<0.001 * *$ \\
\hline Sex & -4.98 & 0.26 & 0.000 & 0.000 & 1.000 \\
\hline Nature of work & -1.73 & 0.09 & -1.65 & -19.40 & $<0.001 * *$ \\
\hline BMI & 0.34 & 0.06 & 0.03 & 0.59 & 0.56 \\
\hline Comorbidities & 0.35 & 0.21 & 0.15 & 1.64 & 0.104 \\
\hline Pain severity & 0.98 & 0.18 & 0.45 & 5.38 & $<0.001 * *$ \\
\hline Diet aggravating frequency of attacks & 1.05 & 0.12 & 0.62 & 8.93 & $<0.001 \% *$ \\
\hline Total of HRQOL & -0.09 & 0.01 & -0.39 & -6.33 & $<0.001 * *$ \\
\hline Constant & 15.81 & 1.12 & & 14.18 & $<0.001 * *$ \\
\hline \multicolumn{6}{|l|}{ Adjusted $\mathrm{R}^{2}=0.855, \mathrm{P}=<0.001 * *$} \\
\hline
\end{tabular}

Table 6. Multiple linear regression analyses for predictor variables of work productivity and activity impairment among the studied subjects ((n=168) ((BMI): body mass index, (HRQOL): Health Related Quality Of Life, (B): Beta Co-Efficient, (SEB): Standard Error)

\begin{tabular}{|c|c|c|c|c|c|}
\hline \multirow{2}{*}{ Predictor Variable } & \multicolumn{2}{|c|}{ Unstandardized Coefficients } & \multirow{2}{*}{$\begin{array}{c}\text { Standardized Coefficients } \\
\beta \\
\end{array}$} & \multirow{2}{*}{$\mathbf{T}$} & \multirow{2}{*}{ p value } \\
\hline & B & SEB & & & \\
\hline Age & -095 & 0.09 & -1.41 & -10.58 & $<0.001 * *$ \\
\hline Nature of work & 0.49 & 0.24 & 0.10 & 2.05 & $0.042 *$ \\
\hline BMI & -0.43 & 0.17 & -0.15 & -2.55 & $0.012 *$ \\
\hline Comorbidities & -12.31 & 1.02 & -1.29 & -12.08 & $<0.001 * *$ \\
\hline No of attacks during year & 2.22 & 0.58 & 0.79 & 3.85 & $<0.001 * *$ \\
\hline Pain severity & 9.43 & 1.61 & 1.02 & 5.87 & $<0.001 * *$ \\
\hline Diet aggravating frequency of attacks & 1.79 & 0.23 & 1.16 & 7.71 & $<0.001 * *$ \\
\hline Constant & 123.69 & 5.84 & & 21.19 & $<0.001 * *$ \\
\hline Adjusted $\mathrm{R}^{2}=0.670, \mathrm{P}=<0.001 * *$ & & & & & \\
\hline
\end{tabular}

Table 7. Correlation between quality of life and work productivity and activity impairment among the studied subjects (n=168).

\begin{tabular}{|l|l|c|}
\hline \multicolumn{1}{|c|}{$r-\backslash p$ values } & \multicolumn{2}{|c|}{ Total of work productivity and activity impairment } \\
\cline { 2 - 3 } Variables & r-test & P-value \\
\hline Total of quality of life & -0.567 & $<0.001 * *$ \\
\hline
\end{tabular}

$* *=$ Highly statistically significant at $\leq 0.01$, Weak $=$ indicates $(\mathrm{r}<0.5)$, Good $=$ indicates $(\mathrm{r}>0.5-0.75)$, Fair $=$ indicates $(\mathrm{r}=0.5)$, Very good $=$ indicates $(r>0.75)$.

Table 3. Reveals that the highest mean percentage of different dimensions for QOL was regarding the limitations either due to physical health or due to emotional problems constituting $100.0 \%$, which reflects the most affected aspect of life due to gout

Table 4. Shows the mean score of work productivity and activity impairment. Where, percent of work productivity loss due to gout during last seven days was mainly affected as well as social / family activity with a mean score of $(74.3 \pm 30.8$ and $56.4 \pm 22.3$, respectively).

Table 5. Presents that QOL among the studied subjects was best predicted by diet aggravating frequency of attacks, pain severity, number of attack, nature of work as well as BMI, presence of comorbidities and age accounting for $67.0 \%$ of the variance of quality of life.
Table 6. Presents that work productivity and activity impairment among the studied subjects was best predicted by diet aggravating frequency of attacks, pain severity, nature of work, age as well as, QOL accounting for $85.5 \%$ of the variance of work productivity.

Table 7. Shows that there was negative and significant correlation $\left(\mathrm{p}=<0.001^{* *}\right)$ between quality of life with work productivity and activity impairment where the higher the quality of life score the lower the work productivity and activity impairment

\section{Discussion}

The study aimed to assess factors affecting quality of life and work productivity among patients with gout. 
According to Socio-demographic characteristics of the studied sample, the present study results showed that, it was observed that, the mean age of participants was $(45.74 \pm 6.87)$ years. It also showed that more than half of them were male. These findings were congruent with [19], who stated that $(52 \%)$ were males. However the majority of participants were between 16 to 36 years (62\%) and only $5 \%$ over 55 years. While these finding were not in accordance with [20] who stated that, the mean age of the participants was 66 years, 92\% were males. Moreover, less than half their body mass index was $30-32 \mathrm{k} / \mathrm{m}^{2}$ with a mean of (31.46 \pm 1.62$)$. This finding was in the same line with [21] who stated that there were $29.1 \%$ of the patients with a BMI of $\geq 30 \mathrm{~kg} / \mathrm{m}^{2}$.

As well, the present study revealed in illness related data of the studied subjects that, about three fifths of participants had comorbid disease and half of them had $<5$ attacks during the last year. These finding were congruent with [22], who found that, the most common comorbidities among the three groups were hypertension, dyslipidemia, and diabetes and $68 \%$ of these patients had one or more gout flares during the 12-month follow-up.

Also was shown that, three quadrants of study subjects had polyarticular affection and approximately the majority of them were complaining from acute pain in other joints as, ankle, knee, hands and pelvis during attack, especially in joints of foot, and more than half of them had severe pain, as well as frequency of attacks was aggravated by increased eating red meat and sea food among most of them, followed by increased eating of beans. This was because of gout is increased by the frequent consumption of foods high in purines, including meats, seafood, certain vegetables and beans, and foods containing fructose. These finding were consistent with [23], who stated that gout is frequently cause polyarticular affection, increased meat and seafood intake were associated with 1.41-fold and 1.51-fold increases in risk for gout. Also, [24] found that ankle and mid-foot involvement are also among the most commonly involved joints in patients with gout with early onset gout.

Concerning QOL, the present study revealed that the highest mean percentage of different dimensions for QOL was regarding the limitations either due to physical health or due to emotional problems constituting $100.0 \%$, which reflects the most affected aspect of life due to gout. These finding was consistent with [25], who said that gout had a greater impact on physical HRQOL compared to other domains. Also, [26] stated that gout patients experience severe pain in affected joints, resulting in substantial limitations in physical functioning.

Regarding work productivity and activity impairment, the present study showed that gout had an effect on work productivity loss as well as activity impairment (social). This might be due to more than half of study subjects had severe pain and three fifth of them their work required physical effort. This finding was in the same line with [27], in a study about the impact of gout on work absence and productivity, who stated that gout, has a substantial impact on work absence and may also negatively impact productivity. Also, [28] added that flares in patients with chronic gout refractory to conventional therapy significantly affect patient work productivity and social activities. Moreover, [29] reported that gout has significant and clinically meaningful impact on work productivity, physical HRQoL and utilities independent of other health conditions.

In relation to predictor variables of quality of life, the present study showed that QOL among the studied subjects was best predicted by diet aggravating frequency of attacks, pain severity, number of attack, nature of work, BMI, presence of comorbidities as well as age accounting for $67.0 \%$ of the variance of health related quality of life, answering research question (1). These findings might be due to less than half of them had 5 and more attack in the last year, aggravated mainly by diet which reflect the effect of pain due to attack on quality of life. Also might be due to healthcare resource utilization, a task complicated by the presence of the other ailments. These finding were consistent with [30] who found that diseaserelated variables were strongly associated with functional disability and the physical component in the unadjusted analyses. After adjusting for age, gender and the other confounders, variables indicating chronic disease (disease duration, polyarticular joint involvement, presence of tophi) and uncontrolled joint inflammation (swollen and tender joints, attacks in the last months and current use of non steroidal anti-inflammatory drugs or colchicine) still showed statistically and clinically significant associations with the Health Assessment Questionnaire Disability Index(HAQ-DI) and Physical Component Summary(PCS) scores. The Mental Component Summary (MCS) score was only influenced by acute symptom-related variables. Also, [31] who stated that total pain, depression, and colchicine use were the most powerful predictors of functional disability in gout population from China. Cardiovascular disease, number of flares/last year, total pain, presence of tender joints, depression, and anxiety were independently risk factors for HRQoL. Also, [32] stated that gout associates with poor overall QOL mainly resulting from associated co-morbidity. Physical health-related QOL, however, remains impaired after adjustment for co-morbidities.

In relation to predictor variables of work productivity, the present study showed that work productivity and activity impairment among the studied subjects was best predicted by pain severity, QOL, diet aggravating frequency of attacks, nature of work as well as age, accounting for $85.5 \%$ of the variance of work productivity answering research question (2). These finding were in the same line with [33], who pointed out that the presence of tophi and more frequent flares was often associated with significantly greater impairment in daily activities. Also with [27] who revealed in their study that,employees with gout may be unable to maintain positions that require strenuous activity, positions that are often paid on an hourly basis or are more likely to include overtime status. They are therefore less likely to choose positions that include manual labor, managing their disease by the amount of activity they perform. Also it was shown that work productivity loss was greater in younger workers. Relative to workers 20-39 years of age, workers in the 4064-year age group had approximately 1.4 times less absenteeism, presenteeism, and overall work impairment [34]. Moreover, [33] stated in their study thatafter adjustment for age, and time since diagnosis. Flares were also associated with greater activity impairment. 
The present study also showed that there was a negative and significant correlation $\left(\mathrm{p}=<0.001^{* *}\right)$ between quality of life and work productivity and activity impairment where the higher quality of life score the lower the work productivity and activity impairment. This indicates that there was a relation between QOL and work productivity. So, increasing in the QOL would lead to better work productivity of the patients and lower impairment, answering research question (3), this finding was congruent with Also [35] showed that there is a strongly positive and significant correlation concerning quality of work life and productivity among employees. In other words, the higher the quality of work life, the higher their productivity will be. Additionally, [36] found that there was significant relationship between quality of work life and the productivity of manpower. Moreover [37], who found that improvement of the quality of work life can increase the productivity of the work force.

\section{Conclusion}

According to results this study concluded that, gout had a significant impact on different aspects health related quality of life, and work productivity and activity impairment. Where, they were both affected by pain severity, diet aggravating frequency of attacks, nature of work as well as age. Besides, the impairment on different aspects of life is often negatively associated with impairment in work productivity and activity.

\section{Recommendations}

Based on the results of the study, the following recommendations are suggested :

1. Health educational instruction is required regarding pain management and diet regimen for patients with gout.

2. Further research is required to address new alternatives to improve the health status and increase production among the patient with gout.

\section{Acknowledgements}

The researchers would like to extend their deepest thanks to all health personnel in the outpatient clinics of Benha taching Hospital as well as patients involved in the study for their cooperation in the fulfillment of this study.

\section{References}

[1] Abdel Rehim, H. (2014). Gout. The Egyptian Society of Internal Medicine 2014, 26: 35-39.

[2] Mayo Foundation for Medical Education and Research. (2018). Overview of Gout. Available at https://www.mayoclinic.org/diseases-conditions/gout/symptomscauses/syc-20372897.

[3] Centers for Disease and Prevention. (2018): Gout, Available at: https://www. cdc.gov/ arthritis/basics/gout.html.

[4] Anbar1, K. (2018): Gout causes and risk factors. Available at: https://www.arthritis-health.com/types/gout/gout-causes-and-riskfactors.
[5] Health line Editorial Team, (2016). Gout Complication, Available at: https://www healthline.com /health/ gout-complications.

[6] Johannsdottir, A., Palsson, O., Jonsson, H. And Gudbjornsson, B. (2018). [Gout - a treatable condition].U S National Library of Medicine National Institutes of Health. 104(4):177-186.

[7] Lee, J., Hirsch, D., Terkeltaub, R., Khanna, D., Singh, A., Sarkin, A. And Kavanaugh, A. (2009). Perceptions of Disease and HealthRelated Quality of Life among Patients with Gout. Rheumatology (Oxford). 48: 582-586.

[8] Singh, J. (2014): The Impact of Gout on Patient's Lives: A study of African-American and Caucasian Men and Women with Gout. Arthritis Research \& Therapy. Available at: https://arthritisresearch.biomedcentral.com/articles/10.1186/ar4589.

[9] Fields, T. And Batterman, A. (2018). How Can We Improve Disease Education in People with Gout? CurrRheumatol Rep. 20 (3): 12 .

[10] Larsson I, Arvidsson S, Bergman S. And Arvidsson B. (2009). Patients' Perceptions of Drug Information Given by a Rheumatology Nurse: A phenomenographic study. Musculoskeletal Care. Musculoskelet. Care (2009) (C 2009 John Wiley \& Sons, Ltd.

[11] Hainer, B., Matheson, E. And Wilkes, R. (2014). Diagnosis, Treatment, and Prevention of Gout, Am Fam Physician. 90(12): 831-836.

[12] Roddy, E. And Doherty, M. (2010).Gout. Epidemiology of Gout. Arthritis Res Ther. 12: 223.

[13] Yamane, T. (1967): Statistics an Introductory Analysis. $2^{\text {nd }}$ Ed. New York Harper and Row CO.USA, 213.

[14] Ware, E. And Sherbourne, D. (1992): The RAND-36 Short-Form Health Status Survey: 1. Conceptual framework and item selection. Med Care. 30(6): 473-83.

[15] Abdulmohsen, S., Coons, S., Draugalis, J. And Hays, R. (1997). Translation of the RAND 36-Item Health Survey1.0 (aka SF-36) into Arabic. Available at: https://www.rand.org/content/dam/rand/pubs/ papers/2009/P7995.pdf.

[16] McHorney, A., Ware, E., Lu, R. And Sherbourne, D. (1994). The MOS 36-Item Short-Form Health Survey (SF-36®): III. Tests of Data Quality, Scaling Assumptions and Reliability Across Diverse Patient Groups. Med Care 1994; 32(1): 40-66.

[17] Ware, E., Snow, K., Kosinski, M. And Gandek, B. (1993): SF$36{ }^{\circledR}$ Health Survey Manual and Interpretation Guide. Boston, MA New England Medical Center, the Health Institute, 1993.

[18] Reilly, C., Zbrozek, S. And Duke, E. (1993). The Validity and Reproducibility of A work Productivity and Activity Impairment Measure. Pharmaco Economics 1993; 4(5): 353-365.

[19] Alshammari, I. And Mujtaba, M. (2017): Public Knowledge and Awareness about Gout: A Cross-sectional Study in Qatar; Article no.JPRI.34375 previously known as British Journal of Pharmaceutical Research ISSN: 2231-2919, NLM ID. Available at: http://www.journalrepository.org/media/journals/JPRI 65/2017/Ju n/Mujtaba1742017JPRI34375.pdf.

[20] Khanna, P., Beaton, C., Persselin, J., Hays, R., Furst, D., Paulus, H., Terkeltaub, R., Maranian, P. And Khanna, D. (2011). Impact of Acute Gout Flares on Health Related Quality of Life (HRQOL) and Productivity in Patients with Chronic Gout. Available at https://acr.confex. com/acr/ 2011 / web program /Paper22325.html. Accessed on 5, October, 2011.

[21] Rothenbacher, D., Primatesta, P., Ferreira, A., Cea-Soriano, L. And Rodríguez, L. (2011). Frequency and Risk Factors of Gout Flares in A large Population-Based Cohort of Incident Gout. heumatology, 50(5): 973-981.

[22] Rashid, N., Levy, G., Wu, Y., Zheng, C., Koblick, R. And Cheetham, T. (2015). Patient and Clinical Characteristics Associated with Gout Flares in an Integrated Health care System. Rheumatol Int. 2015; 35(11): 1799-1807.

[23] Saag, K. And Choi, H. (2006). Epidemiology, Risk Factors, and Lifestyle Modifications for Gout. Arthritis Res Ther. 8 (Suppl 1): S2.Published online 2006 Apr 12.

[24] Zhang, B., Fang, W., Zeng, X., Zhang, Y., Ma, Y., Sheng, F., and Zhang, X. (2016): Clinical Characteristics of Early- and LateOnset Gout. A cross-Sectional Observational Study from a Chinese Gout Clinic. Medicine (Baltimore). 2016 Nov; 95(47): e5425. Published online 2016 Nov 28.

[25] Chandratre, P., Roddy, E., Clarson, L., Richardson, J., Hider, S. And Mallen, C. (2013): Health-related quality of Life in Gout: A systematic Review.Rheumatology (Oxford). 52(11): 2031-2040. 
[26] Tatlock, S., Rüdell, K., Panter, C., Arbuckle, R., Harrold, L., Taylor, W. And Symonds, T. (2017): What Outcomes are Important for Gout Patients? In-Depth Qualitative Research into the Gout Patient Experience to Determine Optimal Endpoints for Evaluating Therapeutic Interventions.Patient. 2017; 10(1): 65-79.

[27] Kleinman, N., Brook, R., Patel, P., Melkonian, A., Brizee, T., Smeeding, J. And Joseph-Ridge, N. (2007). The Impact of Gout on Work Absence and Productivity. International Society for Pharmacoeconomics and Outcomes Research (ISPOR). Volume 10(4): 231-237.

[28] Edwards, N., Sundy, J., Forsythe, A., Blume, S., Pan, F. And Becker, M. (2011). Work productivity Loss Due to Flares in Patients with Chronic Gout Refractory to Conventional Therapy. Journal of Medical Economics. Volume 14(1).

[29] Di Bonaventura, M., Andrews, L., Yadao, A. And Kahler, K. (2012). The Effect of Gout on Health-Related Quality of Life, Work Productivity, Resource Use and Clinical Outcomes among Patients with Hypertension. Journal Expert Review of Pharmacoeconomics and Outcomes Research. 12(6): 821-9.

[30] Scirè,C., Manara, M., Amedeo Cimmino, M., Govoni, M., Salaffi, F., Punzi, L., Monti, M., Carrara, G., Montecucco, C., MatucciCerinic, M. And Minisola, G. (2013): Gout Impacts on Function and Health-Related Quality of Life Beyond Associated Risk Factors and Medical Conditions: Results from the KING Observational Study of the Italian Society for Rheumatology (SIR). Arthritis Res Ther. 15(5): R101.

[31] Fu, T., Cao, H., Yin, R., Zhang, L., Zhang, Q. Li, L. And Gu, Z. (2017). Associated Factors with Functional Disability and Health-Related Quality of Life in Chinese Patients with Gout: a case-control study. Available at: https://bmc musculoskeletdisord. Bio med central .com/ articles/10.1186/s12891-017-1787-7.

[32] Roddy E, Zhang W. And Doherty M. (2007): Is Gout Associated with Reduced Quality of Life? A case-Control study. Rheumatology. 46(9):1441-1444.

[33] Khanna, P., Nuki, G., Bardin, T., Tausche, A., Forsythe, A., Goren, A., Vietri, J. And Khanna, D. (2012). Tophi and Frequent Gout Flares are Associated with Impairments to Quality of Life, Productivity, and Increased Healthcare Resource Use: Results from A Cross-Sectional Survey. Health Qual Life Outcomes. 22; 10:117.

[34] Di Bonaventura, M., Gupta, S., McDonald, M., Sadosky, A. Pettitt, D. And Silverman, S. (2012). Impact of Self-Rated Osteoarthritis Severity in Anemployed Population: CrossSectional Analysis of Data from the National Health and Wellnesssurvey. Health and Quality of Life Outcomes, 10:30 http://www .hqlo.com/ content/10 /1/ 30 .

[35] Mousavi, S., Monfared, S. And Heidary, A. (2011). Investigating the Relationship between Life Quality and Productivity in Physical Education Office Employees in Zanjan Province. Procedia Social and Behavioral Sciences 15 (2011) 3665-3668.

[36] Adel Salavati, A., Maghsoudi, K. And Hasani, K. (2013). Relationship between Quality of Work Life and the Productivity of Manpower.Management and Administrative Sciences Review ISSN: 2308-1368. 2 (3): 243-253.

[37] Hatam, N., Zarifi, M., Lotfi, M., Kavosi, Z. And Tavakoli, A. (2014). The relationship between quality of work life and human resource productivity in knowledge workers. Journal of Management and Informatics. Vol 1, No 3 (2014). 